\title{
Acute inferior wall myocardial infarction associated with complete atrioventricular block and left posterior hemiblock
}

\author{
L. Schamroth, F. Ziady, and J. de Kock \\ From the Baragwanath Hospital and the University of the Witwatersrand, Fohannesburg; and the H.F. Verwoerd \\ Hospital and the University of Pretoria, S.A.
}

\begin{abstract}
Three cases of acute inferior wall myocardial infarction associated with complete atrioventricular block and a junctional escape rhythm showing left posterior hemiblock are presented. The triad appears to constitute a distinct syndrome. It is postulated that the subsidiary pacemaker is situated either in the bundle of His or the proximal part of the anterior division of the left bundle-branch.
\end{abstract}

When complete atrioventricular block complicates acute myocardial infarction it is usually (though not invariably) associated with an inferior or posteroinferior infarction (Julian, Valentine, and Miller, 1964; Norris, 1969; Johansson, 1966). The subsidiary escape pacemaker is, under this circumstance, usually junctional or infranodal, and the resulting QRS complex is narrow since complicating bundle-branch block is rare in the absence of anterior wall coronary artery disease. Despite the absence of complete bundle-branch block, however, intraventricular conduction of the junctional impulse may show the presence of a conduction disturbance in one of the divisions of the left bundlebranch, i.e. a hemiblock. This has not received sufficient emphasis. Most reported cases describe left anterior hemiblock ${ }^{1}$ (Cerqueira-Gomes et al., 1970). Isolated posterior hemiblock is very rare (De Kock and Schamroth, 1974; Rosenbaum, Elizari, and Lazzari, 1970; Wagner and Rosenbaum, 1972).

The following presentation describes three cases of acute inferior wall myocardial infarction associated with complete atrioventricular block, the junctional escape rhythm reflecting a left posterior hemiblock. The triad appears to constitute a distinct syndrome.

Received 31 October 1974.

${ }^{1}$ Recent elegant work by Demoulin and Kulbertus (1972) showed that the left bundle-branch has, in effect, more than two fascicles. Nevertheless, the left bundle-branch appears to 'behave' electrophysiologically as if there were only two major fascicles. This anatomical revelation does not, therefore, appear to detract materially from the electrophysiological hypothesis of hemiblocks.

\section{Case reports}

\section{Case I}

A 78-year-old man with severe praecordial chest pain was admitted to the coronary care unit. There was no measurable blood pressure and he was in a state of cardiogenic shock. A temporary pacemaker was inserted but he remained in cardiogenic shock until the advent of asystole and death five hours later.

The electrocardiogram (Fig. I) showed the features of acute inferior wall myocardial infarction as evidenced by raised and coved ST segments, low to inverted $T$ waves, with $q$ waves in leads II, III, and aVF. The ventricular activation time was increased to $0.06 \mathrm{~s}$, representing the presence of acute injury block. Reciprocal ST segment depression was present in leads VI to V6, in I, and in aVL. The sinus rhythm represented a rate of 88 a minute. The $\mathbf{P}$ waves were completely dissociated from the $Q R S$ complexes: compare, for example, the $P$ wave in lead I which is almost superimposed on the QRS complex, and the $P$ wave in lead aVL which occurs 0.33 s, before the $Q R S$ complex.

The QRS complexes were narrow and reflected right axis deviation of + IIO degrees, thereby resulting in a relatively tall $R$ wave in lead III. The $R R$ interval measured $\mathrm{r} .53 \mathrm{~s}$, representing a subsidiary junctional rhythm of 39 beats a minute.

Comment The electrocardiogram shows the classic 'SIQ3 T3' pattern of left posterior hemiblock. The prominent $q$ waves in leads II, III, and aVF could thus represent the pure manifestation of the left posterior hemiblock, and not necessarily the 'necrosis' of inferior wall myocardial infarction. The presence of the infarction is, however, evident from the presence of the abnormal ST segments and T waves, and the injury block is represented by the delayed ventricular activation time. 

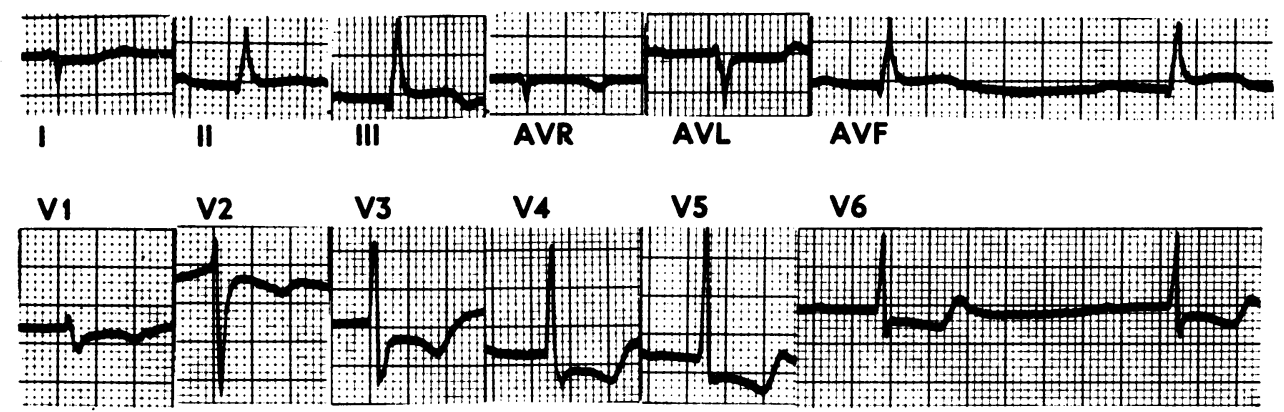

FIG. I Electrocardiogram (Case I) showing complete atrioventricular block and junctional rhythm with left posterior hemiblock, complicating acute inferior wall myocardial infarction.

\section{Case 2}

A 48-year-old woman presented with a typical acute myocardial infarction. Her blood pressure was $90 / 60$ $\mathrm{mmHg}(12.0 / 8.0 \mathrm{kPa})$. She developed transitory asystole during insertion of a temporary pacemaker. She was paced for approximately two days before the return of conducted sinus rhythm. She was discharged from hospital after 22 days.

The electrocardiogram (Fig. 2) showed the features of the hyperacute phase of inferior wall myocardial infarction. This was evidenced by the pronounced slope elevation of the ST segments and the tall and widened $T$ waves in leads II, III, and aVF. In addition, there was an increased ventricular activation time in the same leads, representing acute injury block. There is reciprocal ST segment depression in leads VI to $V_{3}, I$, and aVL.

The PP interval measured $0.45 \mathrm{~s}$, representing a sinus tachycardia of 133 beats a minute. The $P$ waves were completely dissociated from the QRS complexes. The $R R$ interval measured $\mathrm{I} .30 \mathrm{~s}$, representing a lower nodal or junctional rhythm of 46 beats a minute. The mean manifest frontal plane QRS axis was directed at +100 degrees. This right axis deviation resulted in a tall $R$ wave in lead III, which together with the prominent $S$ wave in lead I and the $q$ wave in lead II, constituted the features of a left posterior hemiblock.

\section{Case 3}

A 49-year-old man was admitted to the coronary care unit with a typical clinical presentation of acute myocardial infarction. He developed ventricular fibrillation 5 hours after admission. Defibrillation resulted in ventricular asystole, and further attempts at resuscitation failed.

The electrocardiogram (Fig. 3) showed the features of the hyperacute phase of acute inferior wall myocardial infarction. This was evidenced by the slope elevation of the ST segments and the relatively tall and widened T waves in leads II, III, and aVF. The increased ventricular activation time of $0.07 \mathrm{~s}$, in these leads reflected the presence of acute injury block. The tall $R$ waves in the right praecordial leads probably represented true posterior extension.

The PP intervals (e.g. in lead aVR) measured $0.60 \mathrm{~s}$, representing a sinus tachycardia of roo beats a minute. The $\mathbf{P}$ waves were completely dissociated from the QRS

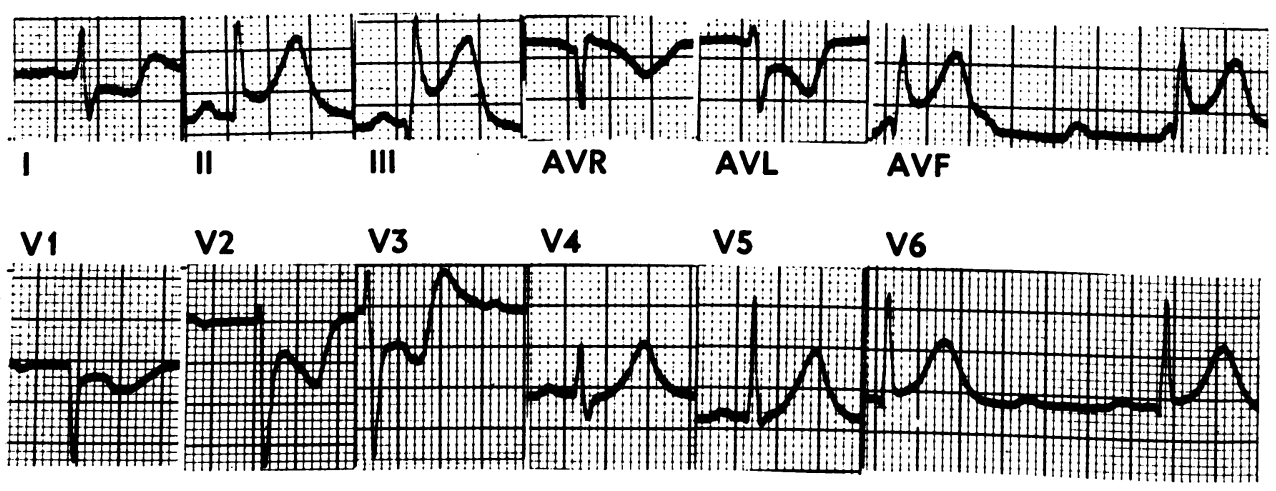

FIG. 2 Electrocardiogram (Case 2) showing complete atrioventricular block with left posterior hemiblock complicating the hyperacute phase of inferior wall myocardial infarction. 


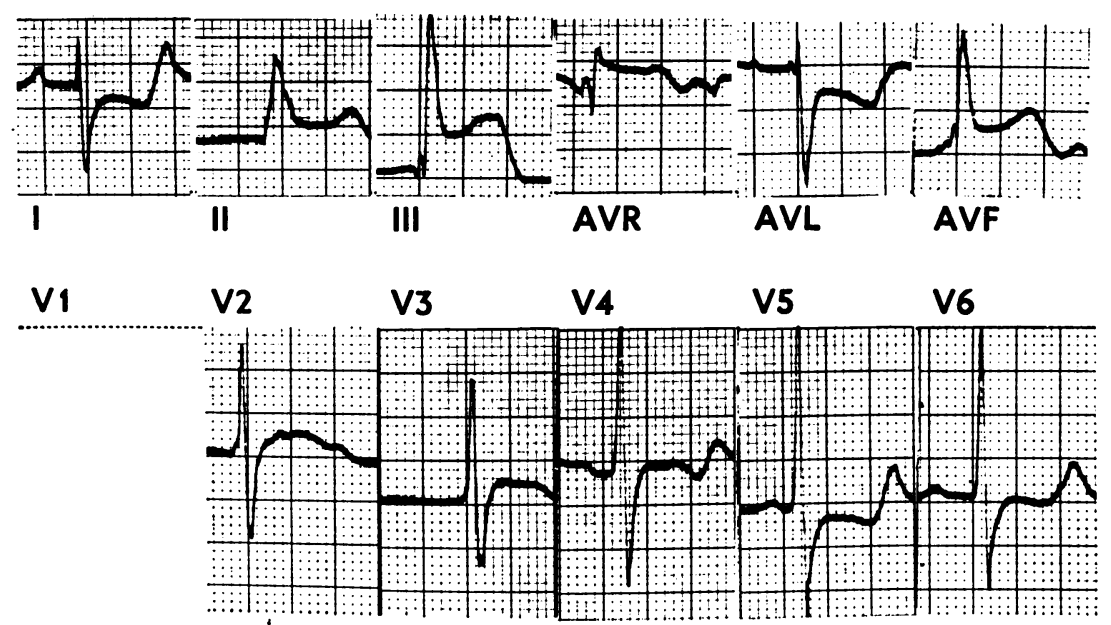

FIG. 3 Electrocardiogram (Case 3) showing complete atrioventricular block with left posterior hemiblock complicating the hyperacute phase of infer ior wall myocardial infarction.

complexes. The $R R$ interval (not illustrated) measured r.30 s, representing a lower nodal or junctional rhythm of 45 beats a minute.

The mean manifest frontal plane $Q R S$ axis is directed at +120 degrees. This right axis deviation results in the very tall $R$ wave in lead III, which, together with the prominent $\mathbf{S}$ wave in standard lead $I$ and notched initial deflection (q equivalent) in leads III and aVF, constitute the features of left posterior hemiblock.

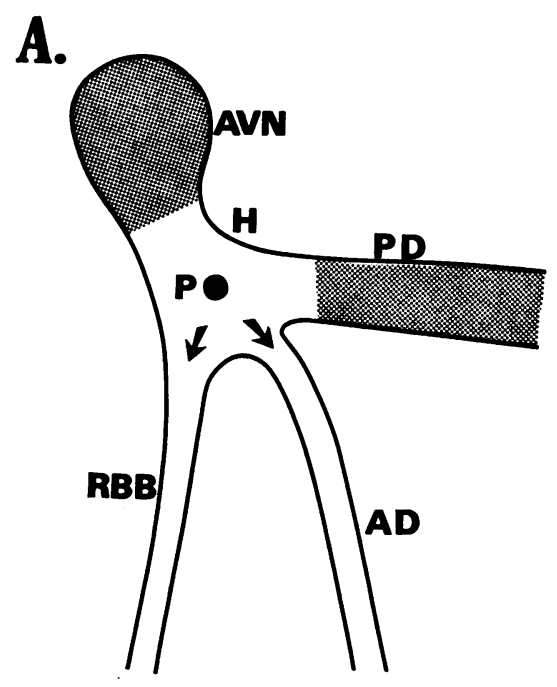

\section{Discussion}

The pathology involving the conducting system in these cases, and the site of the subsidiary escape pacemaker is of interest. The atrioventricular node is supplied in 90 per cent of instances by the right coronary artery and in Io per cent by the left circumflex artery (James and Burch, 1958a, b; James, 196I). It is, therefore, not surprising that atrio-

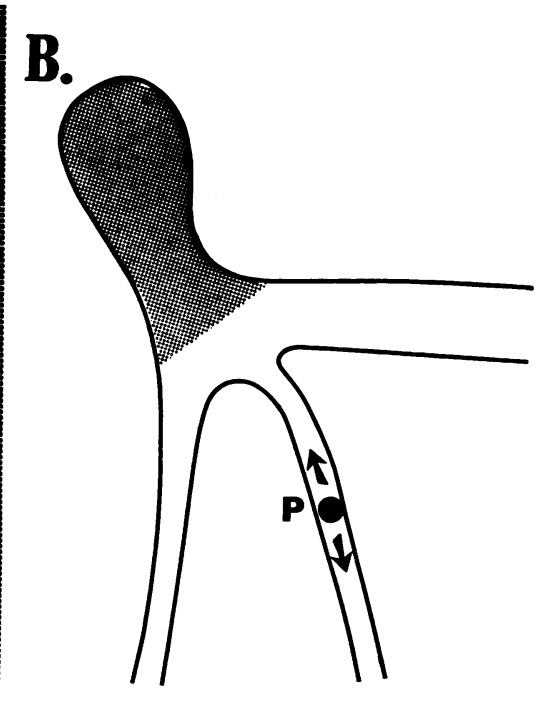

FIG. 4 Diagrams illustrating sites of potential block and postulate locations of subsidiary pacemakers. $A V N$, atrioventricular node; $H$, bundle of His; $P$, pacemaker; $R B B$, right bundlebranch; $P D$, posterior division; $A D$, anterior division. See text. 
ventricular block occurs as a complication of inferior or posteroinferior infarction. The posterior division of the left bundle-branch is more resistant to disease process than the anterior division. It has, among other factors, a double blood supply whereas the anterior division has but a single blood supply, hence the rarity of posterior hemiblock in coronary artery disease (Rosenbaum et al., 1970).

With these factors in mind, the electrocardiographic manifestations of the present cases could be explained on the following bases.

I) The pathology involves the atrioventricular node as well as the posterior division of the left bundle-branch (as illustrated in diagram $A$ of Fig. 4). The pacemaker is, under this circumstance, located in the bundle of His. The hypothesis presupposes that the anterior blood supply to the posterior division has been previously compromised, and that the advent of the posteroinferior infarction obliterates the remaining posterior blood supply to this division. The hypothesis further presupposes that the compromised anterior blood supply selectively did not involve the anterior division of the left bundle-branch - an unlikely event. The relatively slow junctional rates of 39,46 , and 45 beats a minute also seem to indicate a more distal escape pacemaker. Most atrioventricular nodal rhythms associated with inferior infarction occur in the form of a tachycardia - an idionodal tachycardia. However, the severe clinical states of these patients with the grave attendant prognosis may well indicate the severely compromised blood supply as described above.

2) Another possible mechanism is that the atrioventricular node and proximal part of the bundle of His are affected (as illustrated in diagram B of Fig. 4) and the subsidiary escape pacemaker is located in the anterior division of the left bundle-branch. Conduction thus first occurs in the anterior division resulting, in effect, in a left posterior hemiblock. This mechanism would theoretically, however, also cause some degree of right bundle-branch block - and this did not occur in these three cases.

The relatively slow subsidiary rhythm also favours the more distal location of the escape pacemaker.

We are indebted to the Photographic Unit, Department of Medicine, University of the Witwatersrand for the photographic reproductions.

\section{References}

Cerqueira-Gomes, M., Teixeira Lopes, A. M., Sousa Magalhaes, L., Freitas, S., and Braganca-Tender (1970). Estudo retrospectivo das perturbacoes da conducao intraventricular na populacao de um hospital Geral. Fornal do Medico, 73, 392.

De Kock, J., and Schamroth, L. (1974). Right bundle-branch block associated with transient left posterior hemiblock in a case of acute myocardial infarction. South African Medical fournal, 48, 1237.

Demoulin, J. C., and Kulbertus, H. E. (1972). Histopathological examination of concept of left hemiblock. British Heart fournal, 34, 807.

James, T. N. (196I). Anatomy of the Coronary Arteries. Hoeber Medical Division, Harper \& Row, New York.

James, T. N., and Burch, G. E. (1958a). The atrial coronary arteries in man. Circulation, 17,90.

James, T. N., and Burch, G. E. (1958b). Blood supply of the human interventricular septum. Circulation, 17, 391.

Johansson, B. W. (1966). Complete heart block. A clinical, hemodynamic and pharmacological study in patients with and without an artificial pacemaker. Acta Medica Scandinavica, 180, Suppl. 451.

Julian, D. G., Valentine, P. A., and Miller, G. G. (I964). Disturbance of rate, rhythm and conduction in acute myocardial infarction. A prospective study of 100 consecutive unselected patients with the aid of electrocardiographic monitoring. American fournal of Medicine, 37, 915.

Norris, R. M. (1969). Heart block in posterior and anterior myocardial infarction. British Heart fournal, 31, 352.

Rosenbaum, M. B., Elizari, M. V., and Lazzari, J. O. (1970). The Hemiblocks. Tampa Tracings, Oldsmar, Florida.

Wagner, R., and Rosenbaum, M. B. (1972). Transient left posterior hemiblock. Association with acute lateral myocardial infarction. American fournal of Cardiology, 29, 558.

Requests for reprints to Professor L. Schamroth, I55 Barry Hertzog Avenue, Emmarentia, Johannesburg, South Africa. 